\section{Evaluation of a new filter for leucocyte depletion of blood}

\author{
JANE JOHNSON, VALERIE MIJOVIĆ, B BROZOVIĆ \\ North London Blood Transfusion Centre, Edgware, \\ Middlesex
}

In the majority of patients receiving multiple transfusions, non-haemolytic febrile transfusion reactions (NHFTR) are caused by leucocyte antibodies. The severity of the reaction depends mostly on the absolute number of leucocytes present in the transfused blood as well as on the titre and the type of antibody in the recipient's plasma; the reaction can be prevented or alleviated by administration of leucocyte depleted blood. ${ }^{1-4}$ During the last few years filtration has become a popular method for the preparation of leucocyte depleted blood and several filters are currently available. We wish to present the results of evaluating a new filter for leucocyte depletion of blood, Sepacell R-500 (Asahi Medical Co Ltd, Tokyo, Japan), which has been marketed recently.

\section{Material and methods}

Units of blood were collected into CPDA-1 anticoagulant in single or triple packs (Fenwal FKR 0844 or FKR 1369, Travenol Laboratories Ltd, Thetford, England) and stored at $4^{\circ} \mathrm{C}$ as whole blood or plasma reduced blood for two to five days prior to filtration. The Sepacell filter consists of a circular disc of polycarbonate, densely packed with sheets of polyester fibres. Prior to filtration it is primed with $0.9 \%$ sodium chloride and used according to the manufacturer's instructions. The filtration rate could be observed in the drip chamber which is an integral part of the filter. The duration of filtration was recorded. The blood was weighed before and after filtration and samples were taken for the blood count and bacteriological culture. All the procedures were carried out in a laminar flow cabinet inside the sterile suite.

Red cell, leucocyte, and platelet counts were determined using a Coulter counter Model S Plus (Coulter Electronics, Luton, England). The efficiency of the filter in removing leucocytes and platelets, and the associated red cell loss, were expressed as a percentage of absolute numbers of leucocytes, platelets, and red cells in the blood prior to filtration. In addition, information about the presence or absence of NHFTR was obtained for each of the 13 patients transfused with filtered blood, all of whom had a history of NHFTR in the past.

\section{Results}

A total of 40 filters were used but the results obtained for 13 units of filtered blood were arbitrarily excluded from the analysis because the filtration lasted longer than $40 \mathrm{~min}$ and in most cases was completed by the use of a second filter. For 19 units of whole blood the mean $( \pm S D)$ absolute numbers of leucocytes, platelets and red blood cells were $3 \cdot 2$ $\times 10^{9}\left( \pm 1.04 \times 10^{9}\right), 136.1 \times 10^{9}\left( \pm 43.6 \times 10^{9}\right)$ and $2.25 \times 10^{12}\left( \pm 0.21 \times 10^{12}\right)$, respectively, and after the filtration the mean $( \pm S D)$ percentages of leucocytes and platelets removed and the red blood cells lost were $98.5 \%( \pm 2.0 \%), 80.2 \%( \pm 14.4 \%)$ and $6.3 \%( \pm 5.3 \%)$, respectively. For eight units of plasma reduced blood the mean $( \pm S D)$ absolute numbers of leucocytes, platelets and red blood cells were $2.47 \times 10^{9}\left( \pm 0.37 \times 10^{9}\right), 49.9 \times 10^{9}( \pm 11.6$ $\left.\times 10^{9}\right)$ and $2.30 \times 10^{12}\left( \pm 0.24 \times 10^{12}\right)$, respectively, and after the filtration the mean $( \pm S D)$ percentages of leucocytes and platelets removed and the red blood cells lost were $99.7 \%( \pm 0.4 \%)$, $96.4 \%( \pm 2.8 \%)$ and $10.2 \%( \pm 5.9 \%)$, respectively (Figure).

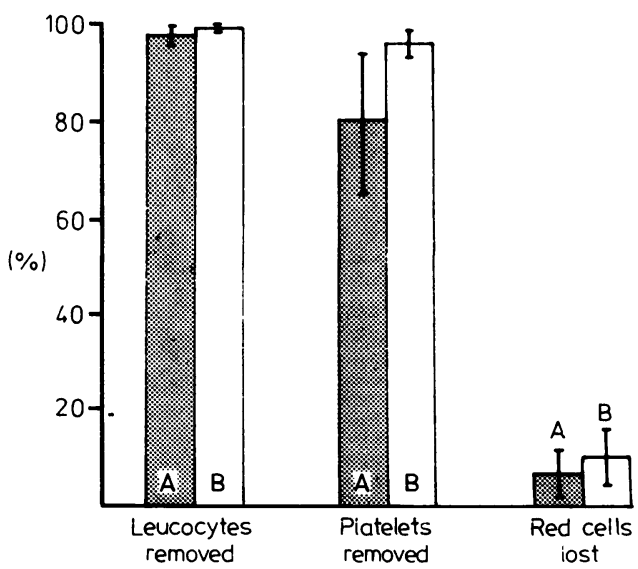

Removal of leucocytes and platelets from whole blood (column A) and plasma reduced blood (column B) and the red cell loss using the Sepacell $R-500$ filter. 
All 27 units of blood which required less than 40 min for filtration (mean $15.9 \mathrm{~min}$ ) were less than four days old (mean 2.9 days). All bacterial cultures were negative. NHFTR was not reported in any of the recipients of the filtered blood.

\section{Discussion and conclusion}

The results showed that the Sepacell removed almost all the leucocytes and most of the platelets present in units of either whole blood or plasma reduced blood. The absolute number of leucocytes which remained in a unit of filtered blood (mean $\left.0.04 \times 10^{9}\right)$ was far less than that $\left(0.5 \times 10^{9}\right)$ usually required to produce NHFTR in a sensitised patient. ${ }^{4}$ The degree of platelet depletion was very high. The difference observed in the platelet depletion between filtered units of whole blood and plasma reduced blood was most likely due to the fact that the plasma reduced blood had had a platelet concentrate prepared from it shortly after collection, and therefore had a lower mean absolute number of platelets $\left(49.9 \times 10^{9}\right)$ than whole blood $(136.1 \times$ $\left.10^{9}\right)$. The red blood cell loss was low, perhaps owing to the small size of the filter.

In our hands, the rate of blood filtration using the Sepacell was considerably faster than the rates of filtration observed using other commercially available filters. It is not clear why the rate of filtration in 13 filters excluded from the evaluation was slow even when a pressure infusor was applied. It has been suggested that the use of blood less than three days old, and thus presumably free from mic- roaggregates which could block the pores of the filter, might resolve the problem, ${ }^{5}$ but in the light of our experience this does not seem likely.

In conclusion, the Sepacell is a highly efficient and fast filter for leucocyte depletion of blood, whose only disadvantage, at present, is a slow rate of filtration in a third of the total number of filters evaluated.

We thank Mr F Fellingham in the Department of Haematology, University College Hospital, for the automated cell counts. We also thank Mr TG Proger of Kimal Scientific Products Ltd, for his helpful co-operation and for supplying the filters.

\section{References}

'Hughes ASB, Brozović B. Leucocyte depleted blood: An appraisal of available techniques. $\mathrm{Br} J$ Haematol 1982;50:381-6.

${ }^{2}$ Mijovic V, Brozovic B, Hughes ASB, Davies TD. Leukocytedepleted blood: A comparison of filtration techniques. Transfusion 1983;23:30-32.

${ }^{3}$ Payne R. The association of febrile transfusion reactions with leuko-agglutinins. Vox Sang 1957;2:233-41.

4 Perkins MA, Payne R, Ferguson J, Wood M. Non-haemolytic febrile transfusion reactions. Quantitative effects of blood components with emphasis on isoantigenic incompatibility of leukocytes. Vox Sang 1966;11:578-600.

5 Sepacell R-500. Technical Information, Asahi Medical Company Limited, Tokyo, 1983.

Requests for reprints to: Miss Jane Johnson, North London Blood Transfusion Centre, Deansbrook Road, Edgware, Middlesex, HA8 9BD, England.

\section{Letters to the Editor}

\section{Deleterious effect of sodium azide on the activity of peroxidase}

Richardson et $a l^{1}$ reported that sodium azide has an inhibitory effect on the activity of peroxidase conjugates. We have made a similar observation with sera containing sodium azide $(0 \cdot 1 \%)$. These sera were tested by Corzyme (Abbott Laboratories, Chicago), which is a competitive enzyme immunoassay (EIA) for the detection of antibody to hepatitis $B$ core antigen (anti-HBc). Anti-HBc in the test serum competes with a constant amount of horseradish peroxidase conjugated anti- $\mathrm{HBc}$ for binding sites on beads coated with hepatitis B core antigen ( $\mathrm{HBcAg}$ ). The proportion of enzyme-conjugated anti-HBc bound to the bead is inversely proportional to the concentration of anti-HBc in the specimen. Thus, within limits, the greater the amount of anti-HBc in the specimen, the lower the absorbance.

Four sera containing $\mathbf{0} \cdot \mathbf{1} \%$ sodium azide, negative for anti-HBc by radioimmunoassay (RIA) were tested by EIA and found to be false-positives. The absorbance value for these sera was very low, thus indicating that the activity of the peroxidase was inhibited. Four anti-HBc positive samples containing $0.1 \%$ sodium azide were also tested by EIA. The effect on the positive sera could not be evaluated due to the nature of the test (Table). Four sera negative for anti-HBc by both RIA and EIA were retested by enzyme assay immedi- ately after adding $0 \cdot 1 \%$ sodium azide and two were found to be false-positive again and in a few other samples absorbance value was significantly reduced. Falsepositive results were not encountered when samples without sodium azide were tested by EIA. The results obtained for these samples by RIA and EIA were similar. This shows that sodium azide has an inhibitory effect on peroxidase when they are in direct contact.

Our experience with sandwich type of $\widetilde{\sigma}$ assays, such as Auszyme II, Ausab EIA 0 and $\mathrm{HBe}$ EIA (Abbott Laboratories, Chicago) showed that sodium azide has no deleterious effect in these tests as azide does not come in direct contact with the peroxidase. 